\section{A brief review on features of falciparum malaria during preg- nancy}

\author{
Alexandre Manirakiza, ${ }^{1}$ \\ Eugène Serdouma, ${ }^{2}$ \\ Richard Norbert Ngbalé, ${ }^{2}$ \\ Sandrine Moussa, ${ }^{1}$ Samuel Gondjé, ${ }^{3}$ \\ Rock Mbetid Degana, ${ }^{3}$ \\ Gislain Géraud Banthas Bata, ${ }^{3}$ \\ Jean Methode Moyen, ${ }^{3}$ Jean Delmont, ${ }^{4}$ \\ Gérard Grésenguet, ${ }^{2}$ Abdoulaye Sepou ${ }^{2}$ \\ ${ }^{1}$ Pasteur Institute of Bangui, Bangui, \\ Central African Republic; ${ }^{2}$ University of \\ Bangui, Bangui, Central African \\ Republic; ${ }^{3}$ Ministry of Public Health, \\ Population and AIDS Control, Bangui, \\ Central African Republic; ${ }^{4}$ Center for \\ Training and Research in Tropical \\ Medicine and Health, Faculty of \\ Medicine North, Marseille, France
}

\begin{abstract}
Malaria in pregnancy is a serious public health problem in tropical areas. Frequently, the placenta is infected by accumulation of Plasmodium falciparum-infected erythrocytes in the intervillous space. Falciparum malaria acts during pregnancy by a range of mechanisms, and chronic or repeated infection and co-infections have insidious effects. The susceptibility of pregnant women to malaria is due to both immunological and humoral changes. Until a malaria vaccine becomes available, the deleterious effects of malaria in pregnancy can be avoided by protection against infection and prompt treatment with safe, effective antimalarial agents; however, concurrent infections such as with HIV and helminths during pregnancy are jeopardizing malaria control in sub-Saharan Africa.
\end{abstract}

\section{Introduction}

Malaria is the cause of significant morbidity and mortality worldwide. In 2015, an estimated 212 million cases of malaria occurred globally, with 429000 deaths. Most cases occurred in tropical countries (90\%), mainly among children under 5 years of age. ${ }^{1}$ Most cases of malaria are caused by either Plasmodium falciparum or $P$. vivax, but almost all deaths are due to falciparum malaria. ${ }^{2}$ Malaria can have devastating consequences on both the mother and the developing foetus. The effects of malaria in pregnancy, due to either $P$. falciparum and $P$ vivax, include maternal anaemia, spontaneous miscarriage, stillbirth, preterm delivery and foetal growth retardation, which increase morbidity and mortality in infancy. ${ }^{3-6}$ In 2007, Dellicour and collaborators estimated that approximately 85 million pregnancies occurred in areas with $P$. falciparum transmission, 54.7 million of which were in areas with stable falciparum malaria, and 31 million were in Africa. ${ }^{7}$

The consequences of falciparum malaria during pregnancy are mediated through a number of mechanisms, and chronic or repeated infections and co-infections have insidious effects. The susceptibility of pregnant women to malaria is due to both immunological and humoral changes, ${ }^{8,9}$ on which research on a malaria vaccine are focused. The adverse effects of malaria in pregnancy vary geographically by malaria transmission intensity. This is thus an important preventable infection, and access to safe, effective antimalarial drugs remains essential. The aim of this study was to synthesise the empirical literature in order to obtain a comprehensive understanding of the pathophysiology, histology and immunology, clinical manifestation and epidemiological features of malaria during pregnancy and also effective antimalarial agents, prevention and co-infections in tropical areas of Africa. A literature search was performed to identify reports on malaria and pregnancy, comprising original research and systematic reviews. No restriction was set on time of publication, but only peer-reviewed publications in English in Medline and PubMed were accessed. The terms used were: malaria AND pregnancy OR malaria AND pregnant OR plasmodium AND pregnancy malaria AND pregnant AND pathophysiology OR histology OR immunology OR clinics OR epidemiology OR antimalarial OR prevention OR HIV AND/OR helminths. Articles were screened on the basis of title and abstract. The flow of retrieval is shown in Figure 1. Recommendations and health policy with regard to malaria during pregnancy were retrieved from the WHO library.

\section{Pathophysiology and histology of placental malaria}

$P$. falciparum can parasitise red blood cells (RBCs) and then adhere to the linings of small blood vessels, thus obstructing perfusion in organs including the heart, lung, brain, liver, kidney, subcutaneous tissues and placenta. ${ }^{10,11}$ Sequestration in the placenta is different from that in other organs, as the RBCs accumulate in the intervillous space $^{12}$ such that the parasite density is often higher than in peripheral blood. ${ }^{10}$ The sequestration allows parasite maturation on
Correspondence: Alexandre Manirakiza, Pasteur Institute of Bangui, Rue Pasteur, PO Box 923, Bangui, Central African Republic. E-mail: amanirak@yahoo.fr

Key words: Malaria; Plasmodium falciparum; pregnancy.

Acknowledgments: we are grateful to Professor Elisabeth Heseltine for editing this manuscript.

Contributions: the authors contributed equally.

Conflict of interests: the authors have no conflict of interests.

Received for publication: 24 March 2017

Revision received: 16 August 2017.

Accepted for publication: 17 August 2017.

This work is licensed under a Creative Commons Attribution NonCommercial 4.0 License (CC BY-NC 4.0).

(C) Copyright A. Manirakiza et al., 2017

Licensee PAGEPress, Italy

Journal of Public Health in Africa 2017; 8:668 doi:10.4081/jphia.2017.668

the placental endothelium, where mature trophozoites and schizonts are often observed. ${ }^{13,14}$ Sequestration is probably possible only from the fourth month of pregnancy, when the anatomical structures of the placenta are already formed. ${ }^{15}$ Lacunar formations in the trophoblast appear between the $10^{\text {th }}$ and $21^{\text {st }}$ day but do not contain maternal blood until the $12^{\text {th }}$ week of pregnancy. ${ }^{15,16}$ The pathophysiological processes that cause adverse foetal effects of malaria in pregnancy are due mainly to accumulation of parasitised RBCs in placental intervillous spaces.

Histologically, inflammatory remodelling is characterized by infiltration of phagocytic cells (monocytes). ${ }^{17-21}$ Sequestration of infected erythrocytes in the placenta triggers beta-chemokine secretion by maternal mononuclear cells, ${ }^{22-24}$ and macrophages and monocytes, attracted by chemotaxis, predominate in the intervillous space, resulting in modification of the spiral microvessels. ${ }^{25}$

These histological changes form a mechanical barrier that reduces intra-placental blood flow and may lead to foetal hypoxia. ${ }^{26}$ The process has been suggested as a cause of intrauterine growth retardation and therefore low birth weight, ${ }^{27-29}$ although it may not be solely responsible, ${ }^{30}$ as disturbance of the transport of nutrients into the placenta by inflammatory lesions may also play a role. ${ }^{31-34}$ 
Placental malaria is determined either on stained slides prepared from placental blood or in stained placental biopsies, a much more sensitive method for detecting placental parasitaemia, ${ }^{35}$ which can detect infections preceding delivery by up to one month by observation of the product of digestion of haemoglobin by the parasite malaria pigment or haemozoin in histological sections. The pathological classification proposed for the phases of placental infestation $^{18}$ is: i) no infection: parasites and malaria pigment absent; ii) acute infection: parasites present, malaria pigment absent; iii) chronic infection: parasites and malaria pigment present; and iv) past infection: no parasites, malaria pigment present.

\section{Immunological changes related to malaria during pregnancy}

\section{Specific humoral immunity to malaria in pregnant women}

All women are not equally susceptible to malaria. The frequency and severity of malaria are greater during a first pregnancy than in subsequent ones, ${ }^{36,37}$ and parasitaemia decreases with parity and maternal age. ${ }^{38}$ People living in malaria-endemic areas who are repeatedly bitten by mosquitoes infected with Plasmodium develop a certain antigenic reaction and immunity due to immunoglobulins $\mathrm{G}$ ( $\operatorname{IgG}$ ), which targets surface antigens of infected erythrocytes known as variant surface antigens VSAs), which are produced by the parasites. They are encoded by a number of genes, organized into multigene families in the parasite chromosomes, and are involved in the adhesion of infected mature erythrocytes (over $18 \mathrm{~h}$ after invasion) in the tissues. The gradual acquisition of partial immunity with repeated exposure to $P$. falciparum-infected mosquito bites (in areas where malaria transmission is stable and intense) is due mainly to acquisition of $\mathrm{IgG}$ directed against the most numerous VSAs present in the parasite population. ${ }^{39,40}$ In pregnant women, the VSA expressed by parasitised RBCs that mediate adhesion to chondroitin sulphate A (CSA) and hyaluronic acid on the syncytiotrophoblasts that line the placental intervillous spaces have unique antigenic properties; ${ }^{14}$ they are fundamentally different from the corresponding antigens expressed on the infected erythrocyte surface in nonplacental $P$. falciparum infections, and are the main target of IgG. ${ }^{9,41}$

The parasite ligand that mediates adhesion of parasitised RBCs to CSA is a conserved antigen, the recognition of which requires a significant change in plasma $\mathrm{IgG},{ }^{42}$ which pointed to the existence of pregnancy-specific VSAs $\left(\mathrm{VSA}_{P A M}\right){ }^{43}$ The dominant VSA on the surface of parasitised $\mathrm{RBCs}$ is $P$. falciparum erythrocyte membrane protein 1 (PfEMP1), which is encoded by the var 2 multigene family. ${ }^{14,26}$ These $\mathrm{VSA}_{P A M}$ are also collectively referred to as VAR2CSA; ${ }^{14,26,44-46}$ other receptors could be involved. ${ }^{45,47}$ Several studies have demonstrated the integral role of VAR2CSA in placental malaria (reviewed in ${ }^{48}$ ). The extracellular region of VAR2CSA includes an N-terminal sequence, six cysteine-rich Duffy binding-like domains and interdomain regions that increasingly appear to play a key role in the adhesion and immunogenicity of recombinant VAR2CSA protein fragments. ${ }^{49,50}$

In non-pregnant women and in men, the antibodies do not recognize $\mathrm{VSA}_{P A M},{ }^{43,51}$ and women living in malaria-endemic areas during their first pregnancy do not yet have specific antibodies and are therefore highly susceptible to malaria infection. In subsequent pregnancies, exposure to $\mathrm{VSA}_{P A M}$ induces the production of specific IgG, ${ }^{42,43,52-54}$ which is detectable at 20 weeks in the first pregnancy but appears earlier and more rapidly in subsequent pregnancies, decreasing after childbirth. ${ }^{55,56} \mathrm{It}$ has been shown experimentally that the serum of multigravidae women exposed to $P$. falciparum malaria inhibits adhesion to CSA of infected erythrocytes from pregnant women, while no inhibition was observed with sera from primigravidae women in early pregnancy or from men. ${ }^{42}$

\section{Others immunological changes related to the susceptibility of pregnant women to malaria}

Pregnancy is associated with decreased immunity. The high protein requirements associated with nutritional deficiency explain a failure of gamma-globulin production, and immunosuppression due to increased cortisol levels in maternal blood has also been proposed. ${ }^{57-60}$ The decrease in cellular immunity during pregnancy makes women susceptible to the infections that are usually controlled by this type of immunity, ${ }^{61,62}$ including malaria. ${ }^{63}$ The frequency of malaria attacks and hyper-parasitaemia during pregnancy have been linked to the state of transient immunosuppression, while humoral immunity against malaria is not affected. ${ }^{64,65}$

\section{Clinical manifestations of malaria in pregnant women}

In regions with high rates of transmis-
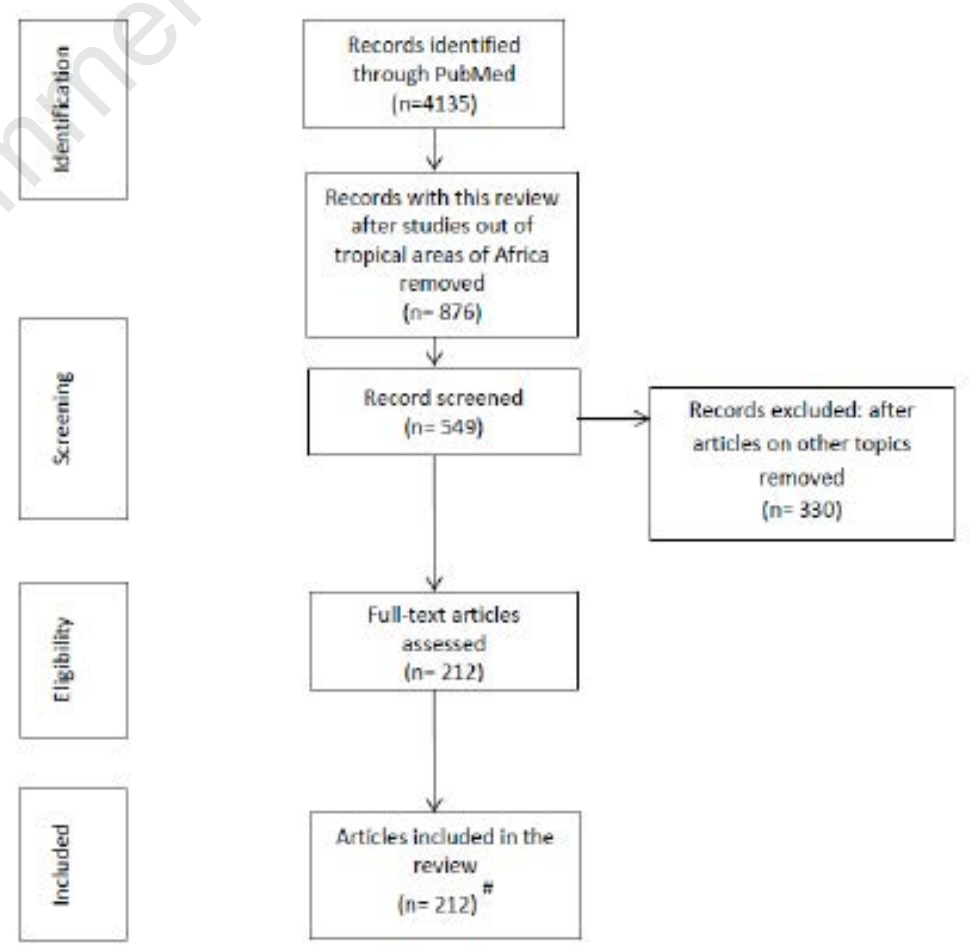

\#Documents accessed on other website like www. who int are taken into account on this flow diagram

Figure 1. Flow diagram of the numbers of articles reviewed. 
sion of malaria, women have considerable immunity to malaria by the time they reach child-bearing age. Nevertheless, they are susceptible to placental malaria during their first or second pregnancy and less so with subsequent pregnancies. ${ }^{66}$ Pregnant women malaria infection more frequently have a higher density of parasites, more malaria episodes, anaemia, severe malaria and mortality. The negative effects on infants include low birth weight due to in utero growth retardation, premature birth, abortion, intrauterine death, neonatal mortality, infant mortality and congenital malaria. Some of the consequences of malaria in pregnancy were described at the beginning of the $20^{\text {th }}$ century ${ }^{67,68}$ and then later. ${ }^{69-74}$ Malaria makes a normal pregnancy a pathological pregnancy, ${ }^{75}$ although its effects manifest differently by gestational age.

Low birth weight and maternal anaemia are major public health problems. At national level, the indicators of malaria control for pregnant women are the percentage of children with a low birth weight and the percentage of women with anaemia during the third trimester of pregnancy. ${ }^{76}$ Anaemia due to malaria in pregnant women is defined by a haemoglobin concentration $\leq 11 \mathrm{~g} / \mathrm{dL} .^{77}$ The syndrome is multifactorial, and its mechanism is still poorly understood but is due to both the destruction of infected and uninfected erythrocytes and inhibition of erythropoiesis. $P$. falciparum induces the production of mediators and inhibitors of erythroid precursors, ${ }^{78-80}$ such as macrophage migration inhibitory factor, ${ }^{81}$ which is increased in the placenta of infected pregnant women and leads to suppression of the formation of erythroid colonies. It acts synergistically with TNF- $\alpha$ and interferon- $\gamma$, which also inhibit haematopoiesis. ${ }^{82}$

In endemic countries, a low birth weight is often associated with intrauterine growth retardation and premature delivery ( $<37$ weeks of gestation). ${ }^{5,83,84}$ Malaria and high placental parasitaemia increase the risk for preterm delivery. ${ }^{85-87}$

\section{Epidemiological features of malaria in pregnant women}

It has long been recognized that the clinical manifestations of malaria in a community are determined by the degree of endemicity of the infection in the local environment and by the age-specific levels of immunity acquired through exposure to infection. ${ }^{65}$ Tables 1 and $2^{88-104}$ detail some of the prevalence of malaria in pregnant women in high-transmission and in lowertransmission areas are, respectively.

In areas of intense, stable transmission of $P$. falciparum, partial immunity leads to clinically latent malaria during pregnancy. Infection is suspected from maternal anaemia and a low-birth-weight infant. ${ }^{105-}$ 107 The best epidemiological indicator of malaria during pregnancy is the prevalence of placental infestation with $P$. falciparum. ${ }^{99,108}$ Nevertheless, the existence of a correlation between parasite load in peripheral blood and cord blood remains controversial. For example, Brabin and Rogerson ${ }^{109}$ reported a correlation between these values, while Ismail and colleagues ${ }^{18}$ reported no parasitaemia in $69 \%$ of samples of peripheral blood but evidence of infection in placental samples. The differences in the results are due partly to geographical variations in malaria epidemiology and partly to the laboratory methods used. In a meta-analysis of 20 studies of peripheral blood and placental parasitaemia, $9 \%$ of placentas and none of the peripheral blood samples were infected. ${ }^{109}$ The sensitivity of microscopy for detecting parasites in the placenta is, however, much lower than that of polymerase chain reaction methods. ${ }^{110}$

The incidence of malaria episodes and the parasite density decrease with the number of pregnancies, and less excess malaria is observed with subsequent pregnancies. ${ }^{11-115}$ In low-transmission areas, women of all gravidities are susceptible to symptomatic, severe maternal disease: miscarriage, stillbirth and congenital malaria are common complications, and malaria is an important cause of low birthweight. ${ }^{116,117}$

\section{Safety and efficacy of antimalarial agents in pregnant women}

The choice of antimalarial drug for pregnant women depends on their tolerance and on the absence of toxicity. The choice should also take into account the period of pregnancy and local efficacy against $P$. falciparum

\section{Chloroquine}

Chloroquine has been widely used to treat falciparum malaria during pregnancy. In 1986, WHO recommended that pregnant women living in malaria-endemic areas receive chloroquine chemoprophylaxis. ${ }^{118}$ Subsequently, alarming evidence of resistance of the malaria parasite to this drug emerged. Steketee and colleagues ${ }^{119}$ reported a $42 \%$ treatment failure in Siaya District, Kenya, in 1986 and a 46\% failure 10 years later. ${ }^{120}$ In the United Republic of Tanzania

Table 1. Median prevalence of maternal malaria parasitaemia in peripheral blood during pregnancy in areas with stable transmission.

\begin{tabular}{llccc} 
Study period & Country & Sample sive & Prevalence (\%) & References \\
$2006-2008$ & Burkina Faso & 1034 & 39.2 & 88 \\
2010 & Burkina Faso & 579 & 18.1 & 89 \\
\hline $1999-2001$ & Cameroon & 770 & 32.8 & 90 \\
$2005-2006$ & Gabon & 203 & 34.4 & 91 \\
\hline 1992 & Gambia & 537 & $27 \%$ & 92 \\
2009 & Ghana & 363 & 28.4 & 93 \\
\hline $1994-1996$ & Kenya & 713 & 45 & 94 \\
$2002-2003$ & Malawi & 1869 & 20.1 & 95 \\
\hline 1996 & Uganda & 853 & 62.1 & 96 \\
$1994-1995$ & United Republic of Tanzania & 1177 & 35.2 & 97 \\
\hline 1993 & United Republic of Tanzania & 389 & 65.5 & 98 \\
1989 & Central African Republic & 229 & 35.6 & 99 \\
\hline
\end{tabular}

Table 2. Median prevalence of maternal malaria parasitaemia in peripheral blood during pregnancy in areas with low transmission.

\begin{tabular}{lccccc} 
Study period & Country & Sample size & Mode of transmission & Prevalence (\%) & Reference \\
1998 & Uganda & 537 & Meso-endemic & 8.6 & 26.2 \\
$2003-2004$ & Sudan & 836 & Meso-endemic & 2.3 & 100 \\
2000 & Ethiopia & 1774 & Seasonal & 17.4 & 101 \\
2001 & Sudan & 175 & Seasonal & 13.7 & 103 \\
\hline 2003 & Sudan & 744 & Seasonal & & 104 \\
\hline
\end{tabular}


in 1991, treatment failed in $35 \%$ of 49 pregnant women. ${ }^{121}$ Curiously, chloroquine was reported to be $100 \%$ effective against falciparum malaria in a study in northern Nigeria in 1993. ${ }^{122}$ In Malawi, Heymann et al. ${ }^{123}$ found that $37 \%$ of pregnant women failed to eliminate $P$. falciparum after 4 weeks of supervised chemoprophylaxis with chloroquine. In 1990, 37.1\% of women in the Central African Republic had placental $P$. falciparum malaria, despite chemoprophylaxis. ${ }^{99}$ In Benin, chemoprophylaxis with chloroquine for 7 months during pregnancy did not prevent placental parasitaemia in $12.7 \%$ of women. ${ }^{124}$ A study in Burkina Faso of the efficacy of chloroquine and sulfadoxine-pyrimethamine (SP) for the prevention of malaria in pregnancy showed a placental parasitaemia prevalence of $18.8 \%$ and $10.6 \%$, respectively. ${ }^{125}$

Because of the increasing resistance of malaria parasites to chloroquine, WHO recommended in 2004 that SP be used as an alternative for the prevention of malaria during pregnancy. ${ }^{126}$

\section{Sulfadoxine-pyrimethamine}

SP is used in pregnant women even though knowledge about its safety is limited. The only suspected form of toxicity is kernicterus with neurotoxicity due to unconjugated bilirubin. Sulphonamides can de-conjugate bilirubin bound to albumin, which would theoretically increase the risk for kernicterus if SP were administered during the third trimester of pregnancy. ${ }^{127}$

Two studies indicate that the SP clears parasites within 48-72 h. ${ }^{128}$ In Malawi, Schultz and colleagues ${ }^{129}$ demonstrated that two curative doses of SP (one in the second trimester and a second in the third trimester) significantly reduced placental parasitaemia. WHO currently recommends intermittent preventive treatment in pregnancy (IPTp) with SP, with two curative doses 1 month apart from the second trimester of pregnancy, the first dose being given between weeks 14 and 20 and the second at least 1 month after the first. ${ }^{126}$ More recently, WHO recommended that IPT be given at every antenatal clinic visit if the visits are at least 1 month apart. ${ }^{130}$

\section{Mefloquine}

Mefloquine has a long half-life, making it useful for IPTp. In Malawi, administration of mefloquine in the second and third trimesters of pregnancy was effective, with good tolerance, although dizziness and abdominal pain were reported. ${ }^{131}$ In Benin, however, a clinical trial showed that two doses of $15 \mathrm{mg} / \mathrm{kg}$ mefloquine in the second and third trimesters, although significantly more effective than SP, were often accom- panied by side-effects such as vomiting, dizziness and physical asthenia; a case of neuropsychiatric disorder was also noted. ${ }^{132}$

\section{Amodiaquine}

Steketee and colleagues ${ }^{133}$ observed a cure rate of $78 \%$ with amodiaquine among women who had parasitaemia under chloroquine chemoprophylaxis. The safety of amodiaquine in pregnancy and especially for the prevention of malaria is not documented. ${ }^{134}$ The drug is considered to be well tolerated by pregnant women, but agranulocytosis, one of its serious sideeffects, limits its use in prophylaxis.

\section{Quinine}

Quinine, which is considered to be well tolerated during pregnancy, is indicated only for curative treatment. The recommended doses must be respected to avoid abortive effects. ${ }^{135-139}$ Quinine has replaced chloroquine in the treatment of malaria in pregnant women, but few clinical trials have been conducted. Harmful effects of quinine during pregnancy have been recognized for a long time, and induction of uterine contractions has been reported. ${ }^{140}$

A study of the safety and efficacy of quinine $(30 \mathrm{mg} / \mathrm{kg}$ per day for 7 days $)$ in Thailand showed side-effects such as dizziness in $42 \%$ of women, ${ }^{141}$ with $4 \%$ parasitaemia on day 7 of treatment and $23 \%$ resurgence of malaria on day 28 of clinical monitoring. A study of the efficacy of the combination of quinine and clindamycin in the second and third trimesters resulted in a $67 \%$ cure rate $(95 \%$ confidence interval, 43 $91 \%$ ) by day 67 of clinical monitoring. ${ }^{142} \mathrm{~A}$ case of $P$. falciparum malaria resistant to quinine in vivo and in vitro was reported in 1988. ${ }^{143}$ Hence, a combination of quinine (30 mg/kg per day) and clindamycin (15 $\mathrm{mg} / \mathrm{kg}$ per day) for 7 days has been suggested for effective treatment of malaria. ${ }^{143,144}$

\section{Artemisinin derivatives}

Artemisinin derivatives are generally well tolerated by pregnant women. Use of drug combinations such as artemetherlumefantrine in the second and third trimesters of pregnancy did not increase the risks for spontaneous abortion, stillbirth or congenital abnormalities when compared with quinine. ${ }^{145}$ The PREGACT study group conducted a randomized, open-label trial between June 2010 through August 2013 to compare the safety and efficacy of artemether-lumefantrine, amodiaquineartesunate, mefloquine-artesunate and dihydroartemisinin-piperaquine in Burkina Faso, Ghana, Malawi and Zambia in women in the second or third trimester of pregnancy. Artemether-lumefantrine was associated with the fewest adverse effects and acceptable cure rates but provided the shortest post-treatment prophylaxis, while dihydroartemisinin-piperaquine was most effective and had an acceptable safety profile. ${ }^{146}$

It has been suggested that artemetherlumefantrine is safe during the first trimester. ${ }^{147}$ A study of birth outcomes of women inadvertently exposed to this combination during the first trimester found no adverse outcomes. ${ }^{148}$ Because of insufficient data on the safety of these drugs during the first trimester of pregnancy, however, WHO recommends their use only during the second and third trimesters. ${ }^{126}$

\section{Dapsone and chlorproguanil}

In a clinical trial in Uganda, minor sideeffects (headache, nausea, sub-jaundice) were reported after use of dapsone-chlorproguanil during pregnancy. ${ }^{149} \mathrm{~A}$ case of hyperbilirubinaemia due to dapsone administered to a pregnant woman for leprosy was reported. ${ }^{150}$ Proguanil and chlorproguanil are well tolerated during pregnancy and have been recommended for prophylaxis against malaria for more than 40 years. Nevertheless, studies of pharmacokinetics showed altered metabolism of proguanil in pregnancy, suggesting that the dose should be increased for pregnant women, ${ }^{151-153}$ which poses a problem of adjustment in the combination with dapsone. In Kenya, Keuter and colleagues ${ }^{154}$ reported that a single dose of chlorproguanil $(1.2 \mathrm{mg} / \mathrm{kg})$ in combination with dapsone $(2.4 \mathrm{mg} / \mathrm{kg})$ was more effective and better tolerated than chloroquine.

The combination of dapsone with pyrimethamine was well tolerated by both the mother and the foetus during pregnancy, with good efficacy against malaria infection. ${ }^{155-158}$

\section{Atovaquone-proguanil}

Atovaquone, usually used to treat Pneumocystis carinii infections, has not been studied for tolerance during pregnancy. McGready and colleagues ${ }^{152}$ reported low plasma concentrations during pregnancy (almost two thirds less than in non-pregnant women) of atovaquone and proguanil, which are used in combination for the treatment of malaria. Use of this combination is still limited because of rapid selection of mutants resistant to atovaquone due to mutations of the cytochrome-b gene of $P$. falciparum. ${ }^{159-161}$

\section{Malaria prevention during pregnancy}

Since 1980, African countries in which malaria transmission is stable have opted for chemoprophylaxis of malaria during 
pregnancy with chloroquine. ${ }^{118}$ The first cases of resistance of $P$. falciparum to chloroquine were reported in Africa in 1980, and cases emerged in Asia during the 1980s. Given the reduced efficacy of chloroquine, many studies have been conducted to find an alternative for preventing malaria during pregnancy. SP has proved to be promising, as shown in many trials after the work of Schultz and colleagues in Malawi. ${ }^{129}$ WHO recommends three strategies to prevent malaria in pregnant women living in endemic areas: ${ }^{126}$ i) four antenatal care visits, during which at least two doses of SP spaced at least 1 month apart are administered in the second trimester of pregnancy; ii) use of insecticide-treated nets to reduce the number of infective bites; and iii) immediate, adequate treatment of malaria. IPTp involves administering curative doses of SP to asymptomatic women (two doses for women with negative HIV status and three doses for women infected with HIV), with at least 1 month between consecutive doses. Because of the risk of embryotoxicity with SP, it should be administered from week 16 of amenorrhoea or week 14 of pregnancy. ${ }^{126}$ This schedule was updated by WHO in 2012 with the recommendation that IPTp be given at every antenatal clinic visit if the visits are at least 1 month apart. ${ }^{130}$

IPTp with SP and use of mosquito nets impregnated with long-lasting insecticide significantly reduce the burden of malaria during pregnancy, and the interventions are cost-effective. ${ }^{162-168}$ IPTp with SP (25 mg sulfadoxine and $1.25 \mathrm{mg}$ pyrimethamine per $\mathrm{kg}$ body weight) reduces the adverse effects of malaria on maternal and fetal health during pregnancy ${ }^{129,169-172}$ and can last up to 60 days in areas where $P$. falciparum strains are fully susceptible. ${ }^{173,174}$ IPTp clears the placenta of possible parasites (therapeutic effect) and prevent further infection (prophylactic effect). ${ }^{175}$

Currently, the main obstacle to this strategy is the emergence and increasing frequency of resistance of $P$. falciparum to SP, already observed in many sub-Saharan African countries. ${ }^{176-183}$ The emergence of resistance is due to accumulation of point mutations in the genes encoding dihydrofolate reductase (DHFR) and dihydropteroate synthase (DHPS), two key enzymes in the metabolic chain of $P$. falciparum. Pyrimethamine and sulfadoxine inhibit DHFR and DHPS, respectively. The number of mutations is correlated with the level of resistance of $P$. falciparum, as shown in vitro. The triple mutant N51I/C59R/SN108 in the DHFR gene and the double
A437G/K540E mutant in the DHPS gene alone or in combination are associated with treatment failure with SP. ${ }^{184}$ Therefore, changes in the level of resistance should be monitored by analysing these resistance markers, ${ }^{185}$ with urgent research for alternatives for malaria prophylaxis during pregnancy. A study in Uganda showed that IPTp with dihydroartemisinin-piperaquine resulted in a lower burden of malaria than did treatment with sulfadoxinepyrimethamine. ${ }^{186}$ The study suggested administration of dihydroartemisinin-piperaquine every 4 weeks from as early as 16 weeks of gestation, which is in the line with the WHO recommendation. ${ }^{130}$

Will vaccination against malaria in pregnancy become possible? An ideal vaccine should simulate all the protective responses that occur in natural infections. A good current candidate is the VAR2CSA antigen, the structure of which differs from that of other PfEMP1 antigens. Identification of a distinct PfEMP1 variant, VAR2CSA as the dominant surface antigen and a clinically important target for a protective immune response to malaria in pregnancy has raised hope. ${ }^{187}$

The VAR2CSA gene displays significant polymorphism, as demonstrated by the number of possible unique antigens that have been produced; however, it is better conserved than other VAR genes, and VAR2CSA retains $75-83 \%$ of its amino acids between isolated strains.

Thus, a limited number of antigens is possible, although the degree of antigenic variation among globally isolated parasite lines has not been determined. ${ }^{188}$ Research on a VAR2CSA-based vaccine includes mapping CSA-binding sites and antibody epitopes, defining Duffy binding-like domains preferentially recognized by immune sera and assessing functional activity by antibodies raised against recombinant Duffy binding-like domains. ${ }^{189,190}$ In 2014, the European Vaccine Initiative hosted a meeting to harmonize clinical development, immunoassays and standards to assess candidate vaccines against placental malaria. The panel concluded that early clinical trials should be conducted of VAR2CSAbased vaccine candidates in women in areas endemic for $P$. falciparum malaria before their first pregnancy. ${ }^{191}$ Currently, a VAR2CSA-based vaccine candidate, PAMVAC, is being tested in Beninese women by an Europian Union funded multi-country consortium (PlacMalVac project, ClinicalTrials.gov NCT02647489). ${ }^{192}$

\section{Co-infections with malaria during pregnancy: an emerging challenge for control \\ Co-infection with $\mathrm{HIV}$}

Co-infection with HIV increases susceptibility to malaria in pregnant women. Malaria and HIV both cause substantial morbidity and mortality, particularly in subSaharan Africa, and it has been estimated that an additional 500000 malaria infections occur each year in pregnant women due to decreased immunity after HIV infection. ${ }^{193}$ Concurrent HIV infection and malaria during pregnancy is a very serious problem for both maternal and child health. ${ }^{194}$ Pregnant women infected with HIV are more likely to have malaria episodes, ${ }^{195,196}$ and the association has a synergistic effect, particularly on severe anaemia, to increase maternal mortality. ${ }^{197,198}$ Several studies (reviewed in ${ }^{193}$ ) also show an increased prevalence of low birth weight $(<2500 \mathrm{~g})$, preterm delivery and intrauterine growth retardation in coinfected women. Co-infection with malaria is also associated with an increased HIV load, increasing the risk for mother-to-child transmission of HIV. ${ }^{199,200}$

Concurrent management of malaria and HIV infection in pregnancy in sub-Saharan Africa is challenging. Medications against the two infections must be administered with pcaution because of interactions and overlapping toxicity (reviewed in ${ }^{201}$ ). For example, co-administration of quinine and protease or non-nucleoside reverse transcriptase inhibitors can be cardiotoxic by inhibiting cytochrome P450 enzyme activity. ${ }^{202}$

HIV-positive women who are not taking co-trimoxazole prophylaxis for opportunistic infections can take a monthly dose of $\mathrm{SP},{ }^{203}$ which is significantly more effective than the two-dose regimen in these women and does not depend on the degree of SP resistance. ${ }^{170,203,204}$ Co-trimoxazole has been shown to decrease malaria morbidity in children and HIV-infected adults ${ }^{205-207}$ because it shares the same drug targets as $\mathrm{SP}$ and is hence effective against protozoan infections. ${ }^{208}$ The first report of the greater effectiveness of co-trimoxazole than IPTp with SP against malari in HIV-infected pregnant women was published in 2011. ${ }^{209}$ In 2014, Denoeud-Ndam et al. ${ }^{210}$ showed that co-trimoxazole alone provided adequate protection against malaria in HIVinfected pregnant women. In light of the increasing prevalence of antifolate-resistant parasites, ${ }^{211}$ however, it is uncertain whether SP and co-trimoxazole will remain effective against malaria. 


\section{Infection with helminths with and without HIV}

Emerging evidence during the past decade has implicated intestinal worm (helminth) infections as important causes of adverse pregnancy outcomes and impaired women's reproductive health (reviewed in 212). Hookworms are important public health threats for women of reproductive age, and a recent study from Gabon reported a $66 \%$ prevalence of intestinal helminths in pregnant women. ${ }^{213}$ In sub-Saharan Africa, hookworm infection is highly prevalent, with almost 99 million cases in women, 37.7 million among women of reproductive age and 6.9 million among pregnant women. ${ }^{214,215}$

The worldwide distribution of helminths, malaria and HIV overlap. ${ }^{216} \mathrm{Co}-$ infection with helminths and malaria parasites cause significant morbidity in the host, particularly in the presence of HIV infection. Malaria in pregnancy due to P. falciparum and helminthic infections in HIVinfected pregnant women are severe public health problems. The prevalence of both malaria and helminths in HIV-infected pregnant women in Ruhuha province in Rwanda was estimated to be $10.1 \% .^{217} \mathrm{~A}$ study in Kenya found that mother-to-child transmission of HIV was significantly higher when the women were co-infected with one or more helminths (48\%) than in women with no helminth infection $(10 \%$; $\mathrm{P}<0.01$; adjusted odds ratio, 7.3 ; $95 \%$ confidence interval, 2.4-33.7). ${ }^{218}$

\section{Conclusions}

Malaria is the commonest tropical parasite-transmitted disease during pregnancy, and, although the problem has been studied widely, there are still major challenges. Malaria infection during pregnancy requires rapid diagnosis and appropriate treatment to avoid complications for the woman and her foetus. Safe, new, effective antimalarial agents are urgently needed, in view of the growing resistance of $P$. falciparum to IPTp, as prophylactic chemotherapy is the main tool for controlling malaria during pregnancy. Special attention should be paid to the management of co-infection with HIV and with helminths, and studies of drug interactions between antiretroviral and antimalarial agents when co-administered in pregnancy are essential.

\section{References}

1. WHO: World Malaria Report 2016. Geneva: World Health Organization;
2016.

2. White NJ, Pukrittayakamee S, Hien TT, Faiz MA, Mokuolu OA, Dondorp AM: Malaria. Lancet 2014;383:72335.

3. Parekh FK, Hernandez JN, Krogstad DJ, et al. Prevalence and risk of Plasmodium falciparum and P. vivax malaria among pregnant women living in the hypoendemic communities of the Peruvian Amazon. Am J Trop Med Hyg 2007;77:451-7.

4. Takem EN, D'Alessandro U. Malaria in pregnancy. Med J Hematol Infect Dis 2013;5:e2013010.

5. Desai M, ter Kuile FO, Nosten F, et al. Epidemiology and burden of malaria in pregnancy. Lancet Infect Dis 2007;7: 93-104.

6. Brabin BJ. An analysis of malaria in pregnancy in Africa. Bull World Health Organ 1983;61:1005-16.

7. Dellicour S, Tatem AJ, Guerra CA, et sl. Quantifying the number of pregnancies at risk of malaria in 2007: a demographic study. PLoS Med 2010;7: e1000221.

8. Raghupathy R. Th1-type immunity is incompatible with successful pregnancy. Immunol Today 1997;18:478-82.

9. Rogerson SJ, Hviid L, Duffy PE, et al. Malaria in pregnancy: pathogenesis and immunity. Lancet Infect Dis 2007; 7:105-17.

10. Duffy PE. Immunity to malaria during pregnancy: different host, different parasite. In: Duffy PE, Fried M, eds. Malaria in pregnancy deadly parasite, susceptible host. London: Taylor \& Francis 2001. pp 70-126.

11. Miller LH, Baruch DI, Marsh K, Doumbo OK: The pathogenic basis of malaria. Nature 2002, 415:673-679.

12. Heddini A. Malaria pathogenesis: a jigsaw with an increasing number of pieces. Int J Parasitol 2002;32:158798.

13. Beeson JG, Amin N, Kanjala M, Rogerson SJ. Selective accumulation of mature asexual stages of Plasmodium falciparum-infected erythrocytes in the placenta. Infect Immun 2002;70:5412-5.

14. Fried M, Duffy PE. Adherence of Plasmodium falciparum to chondroitin sulfate $A$ in the human placenta. Science 1996;272:1502-4.

15. Alsat E, Malassiné A, Tarade A, et al. Le Cytotrophoblaste humain, un cassetête pour le biologiste. Médecine/Sciences 1999;15:1236-43.

16. Fox H. Pathology of the placenta: WB Saunders, 1997. p. 23.

17. Walter PR, Garin Y, Blot P. Placental pathologic changes in malaria. A histologic and ultrastructural study. Am J Pathol 1982;109:330-42.

18. Ismail MR, Ordi J, Menendez C, et al. Placental pathology in malaria: a histological, immunohistochemical, and quantitative study. Hum Pathol 2000;31:85-93.

19. Rogerson SJ, Pollina E, Getachew A, et al. Placental monocyte infiltrates in response to Plasmodium falciparum malaria infection and their association with adverse pregnancy outcomes. Am J Trop Med Hyg 2003;68:115-9.

20. Ordi J, Ismail MR, Ventura PJ, et al. Massive chronic intervillositis of the placenta associated with malaria infection. Am J Surg Pathol 1998;22:100611 .

21. Imamura T, Sugiyama T, Cuevas LE, et al. Expression of tissue factor, the clotting initiator, on macrophages in Plasmodium falciparum-infected placentas. J Infect Dis 2002;186:436-40.

22. Suguitan AL Jr., Leke RG, Fouda G, et al. Changes in the levels of chemokines and cytokines in the placentas of women with Plasmodium falciparum malaria. J Infect Dis 2003;188:107482.

23. Chaisavaneeyakorn S, Moore JM, Mirel L, et al. Levels of macrophage inflammatory protein 1 alpha (MIP-1 alpha) and MIP-1 beta in intervillous blood plasma samples from women with placental malaria and human immunodeficiency virus infection. Clin Diagn Lab Immunol 2003;10:6316.

24. Abrams ET, Brown H, Chensue SW, et al. Host response to malaria during pregnancy: placental monocyte recruitment is associated with elevated beta chemokine expression. J Immunol 2003;170:2759-64.

25. Lyall F. Priming and remodelling of human placental bed spiral ateries during pregnancy - a review. Placenta 2005;26:S31-6.

26. Rogerson SJ, Hviid L, Duffy PE, et al. Malaria in pregnancy: pathogenesis and immunity. Lancet Infect Dis 2007;7:105-17.

27. Zamudio S. The Placenta at high altitude. High Alt Med Biol 2003, 4:171191.

28. Soleymanlou N, Jurisica I, Nevo O, et al. Molecular evidence of placental hypoxia in preeclampsia. J Clin Endocrinol Metab 2005;90:4299-408.

29. Zamudio S. The placenta at high altitude. High Alt Med Biol 2003;4:17191.

30. Kingdom JCP, Kaufmann P. Oxygen ad 
placental villous development: origins of fetal hypoxia. Placenta 1997;18:613.

31. Giudice LC. Insulin-like growth factor family in Graafian follicle development and function. J Soc Gynecol Investig 2001;8:S26-29.

32. Regnault TR, de Vrijer B, Battaglia FC. Transport and metabolism of amino acids in placenta. Endocrine 2002;19:23-41.

33. Zamudio S, Baumann MU, Illsley NP. Effects of chronic hypoxia in vivo on the expression of human placental glucose transporters. Placenta 2006;27:49-55.

34. Tazuke SI, Mazure NM, Sugawara J, et al. Hypoxia stimulates insulin-like growth factor binding protein 1 (IGFBP-1) gene expression in HepG2 cells: a possible model for IGFBP-1 expression in fetal hypoxia. Proc Natl Acad Sci U S A 1998;95:10188-93.

35. Rogerson SJ, Mkundika P, Kanjala MK. Diagnosis of Plasmodium falciparum malaria at delivery: comparison of blood film preparation methods and of blood films with histology. J Clin Microbiol 2003;41:1370-4.

36. Brabin B. An analysis of malaria in pregnancy in Africa. Bull World Health Organ 1983;61:1005-16.

37. Hviid L. [Pregnancy-associated malaria]. Med Trop 2006;66:130-2.

38. Brabin L. Parasitic infections in women and their consequences. Adv Parasitol 1992;31:1-81.

39. Nielsen MA, Staalsoe T, Kurtzhals JA, et al. Plasmodium falciparum variant surface antigen expression varies between isolates causing severe and nonsevere malaria and is modified by acquired immunity. J Immunol 2002;168:3444-50.

40. Bull PC, Lowe BS, Kortok M, et al. Parasite antigens on the infected red cell surface are targets for naturally acquired immunity to malaria. Nat Med 1998;4:358-60.

41. Bull P, Lowe B, Kortok M, et al. Parasite antigens on the infected red cell surface are targets for naturally acquired immunity to malaria. Nat Med 1998;4:358-60.

42. Fried M, Nosten F, Brockman A, et al. Maternal antibodies block malaria. Nature 1998;395:851-2.

43. Ricke CH, Staalsoe T, Koram K, et al. Plasma antibodies from malariaexposed pregnant women recognize variant surface antigens on Plasmodium falciparum-infected erythrocytes in a parity-dependent manner and block parasite adhesion to chondroitin sulfate A. J Immunol
2000;165:3309-16.

44. Beeson JG, Rogerson SJ, Cooke BM, et al. Adhesion of Plasmodium falciparum-infected erythrocytes to hyaluronic acid in placental malaria. Nat Med 2000;6:86-90.

45. Rasti N, Namusoke F, Chene A, et al. Nonimmune immunoglobulin binding and multiple adhesion characterize Plasmodium falciparum-infected erythrocytes of placental origin. Proc Natl Acad Sci U S A 2006;103:13795-800.

46. Fried M, Domingo GJ, Gowda CD, et al. Plasmodium falciparum: chondroitin sulfate $A$ is the major receptor for adhesion of parasitized erythrocytes in the placenta. Exp Parasitol 2006;113:36-42.

47. Beeson JG, Rogerson SJ, Cooke BM, et al. Adhesion of Plasmodium falciparum-infected erythrocytes to hyaluronic acid in placental malaria. Nat Med 2000;6:86-90.

48. Kane EG, Taylor-Robinson AW. Prospects and pitfalls of pregnancyassociated malaria vaccination based on the natural immune response to Plasmodium falciparum VAR2CSAexpressing parasites. Malaria Res Treat 2011;2011:764845.

49. Salanti A, Dahlback M, Turner L, et al. Evidence for the involvement of VAR2CSA in pregnancy-associated malaria. J Exp Med 2004;200:1197203.

50. Tuikue Ndam NG, Salanti A, Bertin G, et al. High level of var2csa transcription by Plasmodium falciparum isolated from the placenta. J Infect Dis 2005;192:331-5.

51. Beeson JG, Brown GV, Molyneux ME, et al. Plasmodium falciparum isolates from infected pregnant women and children are associated with distinct adhesive and antigenic properties. J Infect Dis 1999;180:464-72.

52. Duffy PE, Fried M. Antibodies that inhibit Plasmodium falciparum adhesion to chondroitin sulfate A are associated with increased birth weight and the gestational age of newborns. Infect Immun 2003;71:6620-3.

53. Staalsoe T, Shulman CE, Bulmer JN, et al. Variant surface antigen-specific IgG and protection against clinical consequences of pregnancy-associated Plasmodium falciparum malaria. Lancet 2004;363:283-9.

54. Beeson JG, Mann EJ, Elliott SR, et al. Antibodies to variant surface antigens of Plasmodium falciparum-infected erythrocytes and adhesion inhibitory antibodies are associated with placental malaria and have overlapping and distinct targets. J Infect Dis 2004; 189:540-51.

55. Staalsoe T, Megnekou R, Fievet N, et al. Acquisition and decay of antibodies to pregnancy-associated variant antigens on the surface of Plasmodium falciparum-infected erythrocytes that protect against placental parasitemia. J Infect Dis 2001;184:618-26.

56. O'Neil-Dunne I, Achur RN, AgborEnoh ST, et al. Gravidity-dependent production of antibodies that inhibit binding of Plasmodium falciparuminfected erythrocytes to placental chondroitin sulfate proteoglycan during pregnancy. Infect Immunity 2001;69:7487-92.

57. Bouyou-Akotet MK, Adegnika AA, Agnandji ST, et al. Cortisol and susceptibility to malaria during pregnancy. Microbes Infect 2005;7:1217-23.

58. Vleugels MP, Brabin B, Eling WM, de Graaf R. Cortisol and Plasmodium falciparum infection in pregnant women in Kenya. Trans R Soc Trop Med Hygiene 1989;83:173-7.

59. Rasheed FN, Bulmer JN, Dunn DT, et al. Suppressed peripheral and placental blood lymphoproliferative responses in first pregnancies: relevance to malaria. Am J Trop Med Hyg 1993;48:154-60.

60. Vleugels MP, Eling WM, Rolland R, de Graaf R. Cortisol and loss of malaria immunity in human pregnancy. Br J Obstet Gynaecol 1987;94:758-64.

61. Weinberg ED. Pregnancy-associated depression of cell-mediated immunity. Rev Infect Dis 1984;6:814-31.

62. Okoko BJ, Enwere G, Ota MO. The epidemiology and consequences of maternal malaria: a review of immunological basis. Acta Tropica 2003;87:193-205.

63. Riley EM, Schneider G, Sambou I, Greenwood BM. Suppression of cellmediated immune responses to malaria antigens in pregnant Gambian women. Am J Trop Med Hyg 1989;40:141-4.

64. Hviid L. Naturally acquired immunity to Plasmodium falciparum malaria in Africa. Acta Trop 2005;95:270-5.

65. McGregor IA. Epidemiology, malaria and pregnancy. Am J Trop Med Hyg 1984;33:517-25.

66. Brabin B. An analysis of malaria in pregnancy in Africa. Bull World Health Organ 1983;61:1005-16.

67. Blacklock DB, Gordon RM. Malaria infection as it occurs in late pregnancy, its relationship to labour and early infancy. Ann Trop Med Parasitol 1925;19:327-65.

68. Wickramasuriya GAW. Some observations on malaria occurring in associa- 
tion with pregnancy J Obstet Gynaecol Br Empire 1935;42:816-34.

69. Archibald HM. The influence of malarial infection of the placenta on the incidence of prematurity. Bull World Health Organ 1956;15:842-5.

70. Cannon DS. Malaria and prematurity in the western region of Nigeria. $\mathrm{Br}$ Med J 1958;2:877-8.

71. Gilles HM, Lawson JB, Sibelas M, et al. Malaria, anaemia and pregnancy. Ann Trop Med Parasitol 1969;63:24563.

72. Jelliffe EF. Low birth-weight and malarial infection of the placenta Bull World Health Organ 1968;38:69-78.

73. Reinhardt MC, Ambroise-Thomas P, Cavallo-Serra R, et al. Malaria at delivery in Abidjan. Helv Paediatr Acta 1978;41:65-84.

74. Spitz AJ. Malaria infection of the placenta and its infl uence on the incidence of prematurity in eastern Nigeria. Bull World Health Organ 1959;21:242-4.

75. Bourée P, Bisaroa F, Couzigoub C. Paludisme et grossesse. Revue Francophone des Laboratoires 2008. p 402.

76. WHO: Malaria in pregnancy. Guidelines for measuring key monitoring and evaluation indicators Geneve: WHO; 2007.

77. Koller O. The clinical significance of hemodilution during pregnancy. Obstet Gynecol Surv 1982;37:649-52.

78. Miller KL, Carlino JA, Ogawa Y, et al. Alterations in erythropoiesis in TGFbeta 1-treated mice. Exp Hematol 1992;20:951-6.

79. Miller KL, Schooley JC, Smith KL, et al. Inhibition of erythropoiesis by a soluble factor in murine malaria. Exp Hematol 1989;17:379-85.

80. Yap GS, Stevenson MM. Production of soluble inhibitor of erythropoiesis during Plasmodium chabaudi AS infection in resistant and susceptible mice. Ann N Y Acad Sci 1991;628:279-81.

81. McDevitt MA, Xie J, Shanmugasundaram G, et al. A critical role for the host mediator macrophage migration inhibitory factor in the pathogenesis of malarial anemia. J Exp Med 2006;203:1185-96.

82. Chaiyaroj SC, Rutta AS, Muenthaisong $\mathrm{K}$, et al. Reduced levels of transforming growth factor-beta1, interleukin-12 and increased migration inhibitory factor are associated with severe malaria. Acta Tropica 2004;89:319-27.

83. Guyatt HL, Snow RW. Impact of malaria during pregnancy on low birth weight in sub-Saharan Africa. Clin
Microbiol Rev 2004;17:760-9.

84. Steketee RW, Wirima JJ, Hightower AW, et al. The effect of malaria and malaria prevention in pregnancy on offspring birthweight, prematurity, and intrauterine growth retardation in rural Malawi. Am J Trop Med Hyg 1996;55:33-41.

85. Menendez C, Ordi J, Ismail MR, et al. The impact of placental malaria on gestational age and birth weight. J Infect Dis 2000;181:1740-5.

86. Tako EA, Zhou A, Lohoue J, et al. Risk factors for placental malaria and its effect on pregnancy outcome in Yaounde, Cameroon. Am J Trop Med Hyg 2005;72:236-42.

87. Sullivan AD, Nyirenda T, Cullinan T, et al. Malaria infection during pregnancy: intrauterine growth retardation and preterm delivery in Malawi. J Infect Dis 1999;179:1580-3.

88. Valea I, Tinto H, Drabo MK, et al. An analysis of timing and frequency of malaria infection during pregnancy in relation to the risk of low birth weight, anaemia and perinatal mortality in Burkina Faso. Malaria J 2012;11:71.

89. Cisse M, Sangare I, Lougue G, et al. Prevalence and risk factors for Plasmodium falciparum malaria in pregnant women attending antenatal clinic in Bobo-Dioulasso (Burkina Faso). BMC Infect Dis 2014;14:631.

90. Akum AE, Kuoh AJ, Minang JT, et al. The effect of maternal, umbilical cord and placental malaria parasitaemia on the birthweight of newborns from South-western Cameroon. Acta Paediatr 2005;94:917-23.

91. Bouyou-Akotet MK, Nzenze-Afene S, Ngoungou EB, et al. Burden of malaria during pregnancy at the time of IPTp/SP implementation in Gabon. Am J Trop Med Hyg 2010;82:202-9.

92. D'Alessandro U, Langerock P, Bennett $\mathrm{S}$, et al. The impact of a national impregnated bed net programme on the outcome of pregnancy in primigravidae in The Gambia. Trans R Soc Trop Med Hyg 1996;90:487-92.

93. Wilson NO, Ceesay FK, Obed SA, et al. Intermittent preventive treatment with sulfadoxine-pyrimethamine against malaria and anemia in pregnant women. Am J Trop Med Hyg 2011;85:12-21.

94. Parise ME, Ayisi JG, Nahlen BL, et al. Efficacy of sulfadoxinepyrimethamine for prevention of placental malaria in an area of Kenya with a high prevalence of malaria and human immunodeficiency virus infection. Am J Trop Med Hyg 1998;59:
813-22.

95. Kalilani L, Mofolo I, Chaponda M, et al. The effect of timing and frequency of Plasmodium falciparum infection during pregnancy on the risk of low birth weight and maternal anemia. Trans R Soc Trop Med Hyg 2010;104: 416-22.

96. Ndyomugyenyi R, Magnussen P. Anaemia in pregnancy: Plasmodium falciparum infection is an important cause in primigravidae in Hoima district, western Uganda. Ann Trop Med Parasitol 1999;93:457-65.

97. Menendez C, Ordi J, Ismail MR, et al. The impact of placental malaria on gestational age and birth weight. J Infect Dis 2000;181:1740-5.

98. Matteelli A, Donato F, Shein A, et al. Malarial infection and birthweight in urban Zanzibar, Tanzania. Ann Trop Med Parasitol 1996;90:125-34.

99. Testa J, Awodabon J, Lagarde N, et al. [Interest in placental apposition as an epidemiological marker for malaria]. Bull Soc Pathol Exot 1991;84:473-9.

100. Kasumba IN, Nalunkuma AJ, Mujuzi $\mathrm{G}$, et al. Low birthweight associated with maternal anaemia and Plasmodium falciparum infection during pregnancy, in a peri-urban/urban area of low endemicity in Uganda. Ann Trop Med Parasitol 2000;94:7-13.

101. Omer S, Khalil E, Ali H, Sharief A. Submicroscopic and multiple plasmodium falciparum infections in pregnant Sudanese women. N Am J Med Sci 2011;3:137-41.

102. Newman RD, Hailemariam A, Jimma $\mathrm{D}$, et al. Burden of malaria during pregnancy in areas of stable and unstable transmission in Ethiopia during a nonepidemic year. J Infect Dis 2003;187:1765-72.

103. Elghazali G, Adam I, Hamad A, ElBashir MI. Plasmodium falciparum infection during pregnancy in an unstable transmission area in eastern Sudan. East Mediterr Health J 2003;9:570-80.

104. Adam I, Khamis AH, Elbashir MI. Prevalence and risk factors for anaemia in pregnant women of eastern Sudan. Trans R Soc Trop Med Hyg 2005;99:739-43.

105. Steketee RW, Breman JG, Paluku KM, et al. Malaria infection in pregnant women in Zaire: the effects and the potential for intervention. Ann Trop Med Parasitol 1988;82:113-20.

106. Coulibaly SO, Gies S, D'Alessandro U. Malaria burden among pregnant women living in the rural district of Boromo, Burkina Faso. Am J Trop Med Hyg 2007;77:56-60. 
107. Mutabingwa TK. Malaria and pregnancy: epidemiology, pathophysiology and control options. Acta Tropica 1994;57:239-54.

108. Testa J, Awodabon J, Lagarde N, et al. [Plasmodial indices and malarial placentopathy in 299 parturients in Central Africa]. Med Trop 1990;50:8590.

109. Brabin BJ, Rogerson S. The epidemiology and outcomes of maternal malaria. In: Duffy PE, Fried M, eds. Malaria in pregnancy, deadly parasites, susceptible host. Lndon: Taylor and Fancis. 2001: p. 27-52.

110. Schleiermacher D, Le Hesran JY, Ndiaye JL, et al. Hidden Plasmodium falciparum parasites in human infections: different genotype distribution in the peripheral circulation and in the placenta. Infect Genet Evol 2002;2:97105.

111. Steketee RW, Wirima JJ, Slutsker L, et al Malaria parasite infection during pregnancy and at delivery in mother, placenta, and newborn: efficacy of chloroquine and mefloquine in rural Malawi. Am J Trop Med Hyg 1996;55:24-32.

112. Ofori M, Ansah E, Agyepong I, et al. Pregnancy-associated malaria in a rural community of ghana. Ghana Med J 2009;43:13-8.

113. Nnaji GA, Okafor CI, Ikechebelu JI. An evaluation of the effect of parity and age on malaria parasitaemia in pregnancy. J Obstet Gynaecol 2006;26:755-8.

114. Diagne N, Rogier C, Cisse B, Trape JF. Incidence of clinical malaria in pregnant women exposed to intense perennial transmission. Trans R Soc Trop Med Hyg 1997;91:166-70.

115. Schleiermacher D, Rogier C, Spiegel $A$, et al. Increased multiplicity of Plasmodium falciparum infections and skewed distribution of individual msp1 and msp2 alleles during pregnancy in Ndiop, a Senegalese village with seasonal, mesoendemic malaria. Am J Trop Med Hyg 2001;64:303-9.

116. Nosten F, ter Kuile F, Maelankirri L, et al. Malaria during pregnancy in an area of unstable endemicity. Trans R Soc Trop Med Hyg 1991;85:424-9.

117. Nosten F, Rogerson SJ, Beeson JG, et al. Malaria in pregnancy and the endemicity spectrum: what can we learn? Trends Parasitol 2004;20:42532.

118. WHO: WHO Expert Committee on Malaria, 18th Report. World Health Organ Tech Rep Ser 1986. 735.

119. Steketee RW, Brandling-Bennett AD,
Kaseje DC, et al. In vivo response of Plasmodium falciparum to chloroquine in pregnant and non-pregnant women in Siaya District, Kenya. Bull World Health Organ 1987;65:885-80.

120. Rukaria-Kaumbutho RM, Ojwang SB, Oyieke JB. Resistance to chloroquine therapy in pregnant women with malaria parasitemia. Int $\mathrm{J}$ Gynaecol Obstet 1996;53:235-41.

121. Mutabingwa TK, Malle LN, Mtui SN: Chloroquine therapy still useful in the management of malaria during pregnancy in Muheza, Tanzania. Trop Geogr Med 1991;43:131-5.

122. Okoyeh JN, Lege-Oguntoye L, Emembolu JO, et al. Sensitivity of Plasmodium falciparum to chloroquine in pregnant women in Zaria, northern Nigeria. Trop Geogr Med 1993;45:568.

123. Heymann DL, Steketee RW, Wirima JJ, et al. Antenatal chloroquine chemoprophylaxis in Malawi: chloroquine resistance, compliance, protective efficacy and cost. Trans R Soc Trop Med Hyg 1990;84:496-8.

124. Denoeud L, Fievet N, Aubouy A, et al. Is chloroquine chemoprophylaxis still effective to prevent low birth weight? Results of a study in Benin. Mal J 2007;6:27.

125. Tiono AB, Ouedraogo A, Bougouma EC, et al. Placental malaria and low birth weight in pregnant women living in a rural area of Burkina Faso following the use of three preventive treatment regimens. Mal J 2009;8:224.

126. WHO: A Strategic Framework for Malaria Prevention and Control During Pregnancy in the African Region. AFR/MAL/04/01; Regional Office for African, Brazaville, Congo 2004.

127. WHO. Severe and complicated malaria. Trans R Soc Trop Med Hyg 1990;84.

128. Sowunmi A, Akindele JA, Omitowoju $\mathrm{GO}$, et al. Intramuscular sulfadoxinepyrimethamine in uncomplicated chloroquine-resistant falciparum malaria during pregnancy. Trans R Soc Trop Med Hyg 1993;87:472.

129. Schultz LJ, Steketee RW, Macheso A, et al. The efficacy of antimalarial regimens containing sulfadoxinepyrimethamine and/or chloroquine in preventing peripheral and placental Plasmodium falciparum infection among pregnant women in Malawi. Am J Trop Med Hyg 1994;51:515-22.

130. WHO. Updated WHO policy recommendation: intermittent preventive treatment of malaria in pregnancy using sulfadoxinepyrimethamine
(IPTp-SP). Geneva: World Health Organization, 2012 (http://www. who.int/ malaria/ publications/ atoz/ who_iptp_sp_policy_recommendation/ en/ ). 2012.

131. Steketee RW, Wirima JJ, Slutsker L, et al. Malaria treatment and prevention in pregnancy: indications for use and adverse events associated with use of chloroquine or mefloquine. Am J Trop Med Hyg 1996;55:50-6.

132. Briand V, Bottero $J$, Noel $\mathrm{H}$, et al. Intermittent treatment for the prevention of malaria during pregnancy in Benin: a randomized, open-label equivalence trial comparing sulfadoxine-pyrimethamine with mefloquine. J Infect Dis 2009;200:991-1001.

133. Steketee RW, Brandling-Bennett AD, Kaseje DC, et al. In vivo response of Plasmodium falciparum to chloroquine in pregnant and non-pregnant women in Siaya District, Kenya. Bull World Health Organ 1987;65:885-90.

134. Thomas F, Erhart A, D'Alessandro U. Can amodiaquine be used safely during pregnancy? Lancet Infect Dis 2004;4:235-9.

135. Smith JP. Risky choices: the dangers of teens using self-induced abortion attempts. J Pediatr Health Care 1998;12:147-51.

136. McGready R, Thwai KL, Cho T, et al. The effects of quinine and chloroquine antimalarial treatments in the first trimester of pregnancy. Trans $\mathrm{R}$ Soc Trop Med Hyg 2002;96:180-4.

137. Baragatti M, Fournet F, Henry MC, et al. Social and environmental malaria risk factors in urban areas of Ouagadougou, Burkina Faso. Malaria J 2009;8:13.

138. Lenz W. Malformations caused by drugs in pregnancy. Am J Dis Child 1960;112:99-106.

139. McGready R, Brockman A, Cho T, et al. Randomized comparison of mefloquine-artesunate versus quinine in the treatment of multidrug-resistant falciparum malaria in pregnancy. Trans $\mathrm{R}$ Soc Trop Med Hyg 2000;94:689-93.

140. Maxwell JP. The use of quinine during pregnancy, labour, and the puerperium. Trans R Soc Trop Med Hyg 1908; 1:229-35.

141. McGready R, Cho T, Hkirijaroen L, et al. Quinine and mefloquine in the treatment of multidrug-resistant Plasmodium falciparum malaria in pregnancy. Ann Trop Med Parasitol 1998;92:643-53.

142. McGready R, Cho T, Samuel, et al. Randomized comparison of quinineclindamycin versus artesunate in the 
treatment of falciparum malaria in pregnancy. Trans R Soc Trop Med Hyg 2001;95:651-6.

143. Rolfe M. Multiple drug resistant Plasmodium falciparum malaria in a pregnant indigenous Zambian woman. Trans R Soc Trop Med Hyg 1988;82:554-7.

144. Fripp PJ, Sieling WL. Clindamycin: a second line antimalarial agent. S Afr Med J 1987;72:647.

145. Manyando C, Kayentao K, D'Alessandro U, et al. A systematic review of the safety and efficacy of artemether-lumefantrine against uncomplicated Plasmodium falciparum malaria during pregnancy. Malaria J 2012;11:141.

146. Pekyi D, Ampromfi AA, Tinto H, et al. Four artemisinin-based treatments in African pregnant women with malaria. Malawi Med J 2016;28:139-49.

147. Manyando C, Mkandawire R, Puma L, et al. Safety of artemether-lumefantrine in pregnant women with malaria: results of a prospective cohort study in Zambia. Malaria J 2010;9:249.

148. Mosha D, Mazuguni F, Mrema S, et al. Safety of artemether-lumefantrine exposure in first trimester of pregnancy: an observational cohort. Malaria J 2014;13:197.

149. Kaye DK, Nshemerirwe R, Mutyaba TS, Ndeezi G. A randomized clinical trial comparing safety, clinical and parasitological response to artemetherlumefantrine and chlorproguanil-dapsone in treatment of uncomplicated malaria in pregnancy in Mulago hospital, Uganda. J Infect Dev Countries 2008;2:135-9.

150. Thornton YS, Bowe ET. Neonatal hyperbilirubinemia after treatment of maternal leprosy. South Med J 1989;82:668.

151. Wangboonskul J, White NJ, Nosten F, et al. Single dose pharmacokinetics of proguanil and its metabolites in pregnancy. Eur J Clin Pharmacol 1993;44:247-51.

152. McGready R, Stepniewska K, Edstein $\mathrm{MD}$, et al. The pharmacokinetics of atovaquone and proguanil in pregnant women with acute falciparum malaria. Eur J Clin Pharmacol 2003;59:545-52.

153. McGready R, Stepniewska K, Seaton E, et al. Pregnancy and use of oral contraceptives reduces the biotransformation of proguanil to cycloguanil. Eur $\mathrm{J}$ Clin Pharmacol 2003;59:553-7.

154. Keuter M, van Eijk A, Hoogstrate M, et al. Comparison of chloroquine, pyrimethamine and sulfadoxine, and chlorproguanil and dapsone as treat- ment for falciparum malaria in pregnant and non-pregnant women, Kakamega District, Kenya. BMJ 1990;301:466-70.

155. Greenwood BM, Greenwood AM, Snow RW, et al. The effects of malaria chemoprophylaxis given by traditional birth attendants on the course and outcome of pregnancy. Trans R Soc Trop Med Hyg 1989;83:589-94.

156. Greenwood AM, Armstrong JR, Byass $\mathrm{P}$, et al. Malaria chemoprophylaxis, birth weight and child survival. Trans R Soc Trop Med Hyg 1992;86:483-5.

157. Greenwood AM, Menendez C, Todd J, Greenwood BM. The distribution of birth weights in Gambian women who received malaria chemoprophylaxis during their first pregnancy and in control women. Trans R Soc Trop Med Hyg 1994;88:311-2.

158. Menendez C, Todd J, Alonso PL, et al. Malaria chemoprophylaxis, infection of the placenta and birth weight in Gambian primigravidae. J Trop Med Hyg 1994;97:244-8.

159. Meshnick SR, Trumpower B. Multiple cytochrome B mutations may cause atovaquone resistance. $\mathrm{J}$ Infect Dis 2005;191:822-3.

160. Schwartz E, Bujanover S, Kain KC. Genetic confirmation of atovaquoneproguanil-resistant Plasmodium falciparum malaria acquired by a nonimmune traveler to East Africa. Clin Infect Dis 2003;37:450-1.

161. Gil JP, Nogueira F, Stromberg-Norklit $\mathrm{J}$, et al. Detection of atovaquone and Malarone resistance conferring mutations in Plasmodium falciparum cytochrome b gene (cytb). Mol Cell probes 2003;17:85-9.

162. Rogier C. Challenge of developing anti-parasite vaccines in the tropics. Med Trop 2007;67:328-34.

163. Briand V, Denoeud L, Massougbodji A, Cot M. Efficacy of intermittent preventive treatment versus chloroquine prophylaxis to prevent malaria during pregnancy in Benin. J Infect Dis 2008;198:594-601.

164. van Eijk AM, Ayisi JG, ter Kuile FO, et al. Effectiveness of intermittent preventive treatment with sulphadoxinepyrimethamine for control of malaria in pregnancy in western Kenya: a hospital-based study. Trop Med Int Health 2004;9:351-60.

165. Mbonye AK, Hansen KS, Bygbjerg IC, Magnussen P. Intermittent preventive treatment of malaria in pregnancy: the incremental cost-effectiveness of a new delivery system in Uganda. Trans R Soc Trop Med Hyg 2008;102:685-
93.

166. Schultz LJ, Steketee RW, Chitsulo L, Wirima JJ. Antimalarials during pregnancy: a cost-effectiveness analysis. Bull World Health Organ 1995;73:20714.

167. Sicuri E, Bardaji A, Nhampossa T, et al. Cost-effectiveness of intermittent preventive treatment of malaria in pregnancy in southern Mozambique. PLoS One 2010;5:e13407.

168. Wolfe EB, Parise ME, Haddix AC, et al. Cost-effectiveness of sulfadoxinepyrimethamine for the prevention of malaria-associated low birth weight. Am J Trop Med Hyg 2001;64:178-86.

169. Verhoeff FH, Brabin BJ, Chimsuku L, et al. An evaluation of the effects of intermittent sulfadoxinepyrimethamine treatment in pregnancy on parasite clearance and risk of low birthweight in rural Malawi. Ann Trop Med Parasitol 1998;92:141-50.

170. Parise ME, Ayisi JG, Nahlen BL, et al. Efficacy of sulfadoxinepyrimethamine for prevention of placental malaria in an area of Kenya with a high prevalence of malaria and human immunodeficiency virus infection. Am J Trop Med Hyg 1998;59:813-22.

171. Shulman CE, Dorman EK, Cutts F, et al. Intermittent sulphadoxinepyrimethamine to prevent severe anaemia secondary to malaria in pregnancy: a randomised placebo-controlled trial. Lancet 1999;353:632-6.

172. Rogerson SJ, Chaluluka E, Kanjala M, et al. Intermittent sulfadoxinepyrimethamine in pregnancy: effectiveness against malaria morbidity in Blantyre, Malawi, in 1997-99. Trans R Soc Trop Med Hyg 2000;94:549-53.

173. Watkins WM, Mberu EK, Winstanley PA, Plowe CV. More on the efficacy of antifolates antimalarial combinations in Africa. Parasitol Today 1999; 15:131-2.

174. White NJ. Assessment of the pharmacodynamic properties of antimalarial drugs in vivo. Antimicrob Agents Chemother 1997;41:1413-22.

175. White NJ. Intermittent presumptive treatment for malaria. PLoS Med 2005;2:e3.

176. Ronn AM, Msangeni HA, Mhina J, et al. High level of resistance of Plasmodium falciparum to sulfadoxine-pyrimethamine in children in Tanzania. Trans R Soc Trop Med Hyg 1996;90:179-81.

177. Roper C, Pearce R, Bredenkamp B, et al. Antifolate antimalarial resistance in southeast Africa: a population-based 
analysis. Lancet 2003;361:1174-81

178. Menard D, Djalle D, Manirakiza A, et al. Drug-resistant malaria in Bangui, Central African Republic: an in vitro assessment. Am J Trop Med Hyg 2005;73:239-43.

179. Menard D, Djalle D, Yapou F, et al. Frequency distribution of antimalarial drug-resistant alleles among isolates of Plasmodium falciparum in Bangui, Central African Republic. Am J Trop Med Hyg 2006;74:205-10.

180. Raman J, Little F, Roper C, et al. Five years of large-scale dhfr and dhps mutation surveillance following the phased implementation of artesunate plus sulfadoxine-pyrimethamine in Maputo Province, Southern Mozambique. Am J Trop Med Hyg 2010;82:788-94.

181. Gesase S, Gosling RD, Hashim R, et al. High resistance of Plasmodium falciparum to sulphadoxine/pyrimethamine in northern Tanzania and the emergence of dhps resistance mutation at Codon 581. PLoS One 2009; 4:e4569.

182. Mombo-Ngoma G, Oyakhirome S, Ord $\mathrm{R}$, et al. High prevalence of dhfr triple mutant and correlation with high rates of sulphadoxine-pyrimethamine treatment failures in vivo in Gabonese children. Malaria J 2011;10:123.

183. Ndiaye D, Dieye B, Ndiaye YD, et al. Polymorphism in dhfr/dhps genes, parasite density and ex vivo response to pyrimethamine in Plasmodium falciparum malaria parasites in Thies, Senegal. Int J Parasitol Drugs Drug Resist 2013;3:135-42.

184. Kublin JG, Dzinjalamala FK, Kamwendo DD, et al. Molecular markers for failure of sulfadoxinepyrimethamine and chlorproguanildapsone treatment of Plasmodium falciparum malaria. J Infect Dis 2002;185:380-8.

185. Deloron P, Bertin G, Briand V, et al. Sulfadoxine/pyrimethamine intermittent preventive treatment for malaria during pregnancy. Emerg Infect Dis 2010;16:1666-70.

186. Kakuru A, Jagannathan P, Muhindo MK, et al. Dihydroartemisinin-piperaquine for the prevention of malaria in pregnancy. New Engl J Med 2016;374:928-39.

187. Tuikue Ndam N, Deloron P. Towards a vaccine against pregnancy-associated malaria. Parasite 2008;15:515-21.

188. Bockhorst J, Lu F, Janes JH, et al. Structural polymorphism and diversifying selection on the pregnancy malaria vaccine candidate VAR2CSA.
Mol Biochem Parasitol 2007;155:10312.

189. Bigey P, Gnidehou S, Doritchamou J, et al. The NTS-DBL2X region of VAR2CSA induces cross-reactive antibodies that inhibit adhesion of several Plasmodium falciparum isolates to chondroitin sulfate A. J Infect Dis 2011;204:1125-33.

190. Doritchamou J, Bigey P, Nielsen MA, et al. Differential adhesion-inhibitory patterns of antibodies raised against two major variants of the NTS-DBL2X region of VAR2CSA. Vaccine 2013;31:4516-22.

191. Chene A, Houard S, Nielsen MA, et al. Clinical development of placental malaria vaccines and immunoassays harmonization: a workshop report. Malaria J 2016;15:476.

192. Gbedande K, Fievet N, Viwami F, et al. Clinical development of a VAR2CSAbased placental malaria vaccine PAMVAC: Quantifying vaccine antigenspecific memory B \& $\mathrm{T}$ cell activity in Beninese primigravidae. Vaccine 2017;35:3474-81.

193. ter Kuile FO, Parise ME, Verhoeff FH, et al. The burden of co-infection with human immunodeficiency virus type 1 and malaria in pregnant women in subsaharan Africa. Am J Trop Med Hyg 2004;71:41-54.

194. Steketee RW, Wirima JJ, Bloland PB, et al. Impairment of a pregnant woman's acquired ability to limit Plasmodium falciparum by infection with human immunodeficiency virus type-1. Am J Trop Med Hyg 1996; 55:42-9.

195. van Eijk AM, Ayisi JG, ter Kuile FO, et al. HIV increases the risk of malaria in women of all gravidities in Kisumu, Kenya. Aids 2003;17:595-603.

196. Ticconi C, Mapfumo M, Dorrucci M, et al. Effect of maternal HIV and malaria infection on pregnancy and perinatal outcome in Zimbabwe. $\mathrm{J}$ Acquir Immune Defic Syndr 2003;34:289-94.

197. van Eijk AM, Ayisi JG, ter Kuile FO, et al. Human immunodeficiency virus seropositivity and malaria as risk factors for third-trimester anemia in asymptomatic pregnant women in western Kenya. Am J Trop Med Hyg 2001;65:623-30.

198. Ayisi JG, van Eijk AM, ter Kuile FO, et al. The effect of dual infection with HIV and malaria on pregnancy outcome in western Kenya. AIDS 2003; 17:585-94.

199. Brahmbhatt H, Sullivan D, Kigozi G, et al. Association of HIV and malaria with mother-to-child transmission, birth outcomes, and child mortality. J Acquir Immune Defic Syndr 2008;47:472-6.

200. Brahmbhatt H, Kigozi G, WabwireMangen F, et al The effects of placental malaria on mother-to-child HIV transmission in Rakai, Uganda. AIDS 2003; 17:2539-41

201. Brentlinger PE, Behrens CB, Micek MA. Challenges in the concurrent management of malaria and HIV in pregnancy in sub-Saharan Africa. Lancet Infect Dis 2006;6:100-11.

202. Khoo S, Back D, Winstanley P: The potential for interactions between antimalarial and antiretroviral drugs AIDS 2005;19:995-1005.

203. Filler SJ, Kazembe P, Thigpen M, et al. Randomized trial of 2-dose versus monthly sulfadoxine-pyrimethamine intermittent preventive treatment for malaria in HIV-positive and HIV-negative pregnant women in Malawi. J Infect Dis 2006;194:286-93.

204. Meshnick SR, Mwapasa V, Rogerson SJ. Protecting pregnant women from malaria in areas of high HIV infection prevalence. J Infect Dis 2006;194:2735.

205. Hamel MJ, Greene C, Chiller T, et al. Does cotrimoxazole prophylaxis for the prevention of HIV-associated opportunistic infections select for resistant pathogens in Kenyan adults? Am J Trop Med Hyg 2008;79:320-30.

206. Kamya MR, Gasasira AF, Achan J, et al. Effects of trimethoprim-sulfamethoxazole and insecticide-treated bednets on malaria among HIV-infected Ugandan children. AIDS 2007; 21:2059-66.

207. Thera MA, Sehdev PS, Coulibaly D, et al. Impact of trimethoprim-sulfamethoxazole prophylaxis on falciparum malaria infection and disease. $\mathrm{J}$ Infect Dis 2005;192:1823-9.

208. Brumfitt W, Hamilton-Miller JM: Limitations of and indications for the use of co-trimoxazole. J Chemother 1994;6:3-11.

209. Kapito-Tembo A, Meshnick SR, van Hensbroek MB, et al. Marked reduction in prevalence of malaria parasitemia and anemia in HIV-infected pregnant women taking cotrimoxazole with or without sulfadoxinepyrimethamine intermittent preventive therapy during pregnancy in Malawi. J Infect Dis 2011;203:464-72.

210. Denoeud-Ndam L, Zannou DM, Fourcade C, et al. Cotrimoxazole prophylaxis versus mefloquine intermittent preventive treatment to prevent 
malaria in HIV-infected pregnant women: two randomized controlled trials. J Acquir Immune Defic Syndr 2014;65:198-206.

211. Desai M, Gutman J, Taylor SM, et al. Impact of sulfadoxine-pyrimethamine resistance on effectiveness of intermittent preventive therapy for malaria in pregnancy at clearing infections and preventing low birth weight. Clin Infect Dis 2016;62:323-33.

212. Hotez P, Whitham M. Helminth infections: a new global women's health agenda. Obstet Gynecol 2014;123:15560.
213. Adegnika AA, Agnandji ST, Chai SK, et al. Increased prevalence of intestinal helminth infection during pregnancy in a Sub-Saharan African community. Wien Klin Wochenschr 2007;119:7126.

214. de Silva NR, Brooker S, Hotez PJ, et al. Soil-transmitted helminth infections: updating the global picture. Trends Parasitol 2003;19:547-51.

215. Brooker S, Hotez PJ, Bundy DA. Hookworm-related anaemia among pregnant women: a systematic review. PLoS Neglect Trop Dis 2008;2:e291.

216. Hotez PJ, Brindley PJ, Bethony JM, et al. Helminth infections: the great neglected tropical diseases. J Clin Investigat 2008;118:1311-21.

217. Ivan E, Crowther NJ, Rucogoza AT, et al. Malaria and helminthic co-infection among HIV-positive pregnant women: prevalence and effects of antiretroviral therapy. Acta Tropica 2012;124:17984.

218. Gallagher M, Malhotra I, Mungai PL, et al. The effects of maternal helminth and malaria infections on mother-tochild HIV transmission. AIDS 2005; 19:1849-55. 